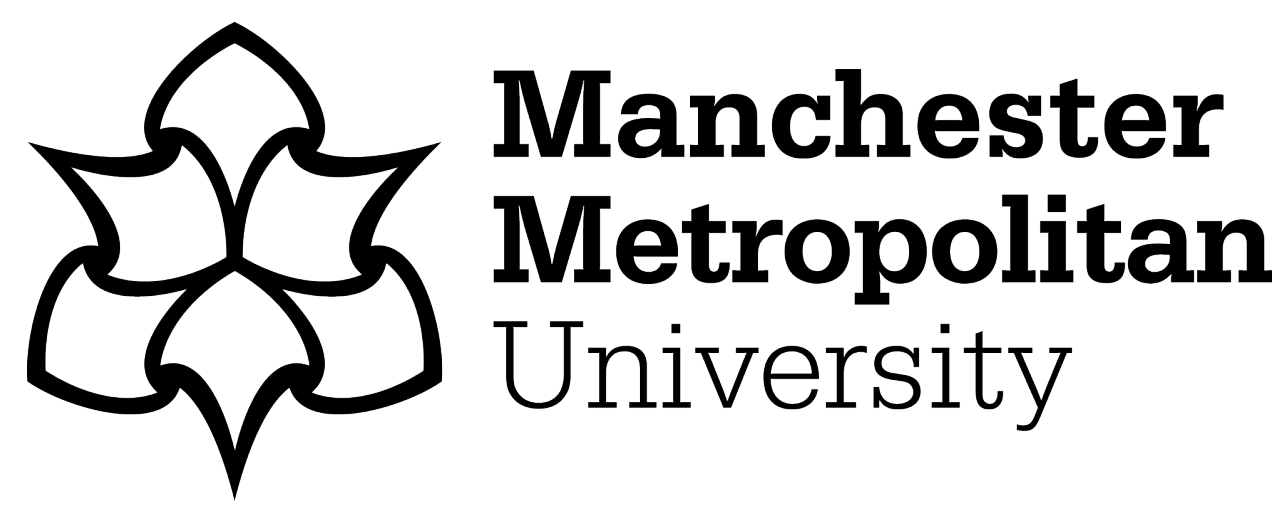

Bell, B ORCID logoORCID: https://orcid.org/0000-0001-6436-2041 and Gallimore, K ORCID logoORCID: https://orcid.org/0000-0001-7937-2357 (2015) Embracing the games? Leverage and legacy of London 2012 Olympics at the sub-regional level by means of strategic partnerships. Leisure Studies, 34 (6). pp. 720-741. ISSN 0261-4367

Downloaded from: https://e-space.mmu.ac.uk/556232/

Version: Accepted Version

Publisher: Taylor \& Francis (Routledge)

DOI: https://doi.org/10.1080/02614367.2014.994553

Please cite the published version 


\title{
Embracing the games? Leverage and legacy of London 2012 Olympics at the sub-regional level by means of strategic partnerships
}

\begin{abstract}
The ability to leverage benefits and establish a legacy from hosting mega events continues to be of significant interest from both academic and policy perspectives. However, relatively few studies have focused on leverage and legacy by cities and regions that are not hosting mega events. This research adds to the evidence base by examining the effectiveness of a sub-regional multi-agency strategic planning process in leveraging benefits from a mega event, the London 2012 Olympics. A case study methodology drew on qualitative data from a number of sources regarding the operation of the multi-agency strategic planning steering group. The multi-agency partnership experienced significant difficulties arising from the external environment, principally the austere economic environment and the extensive structural changes for the public sector in the period prior to the event. Many partners were limited in their ability to deliver the aspirations or leverage the benefits set out in the strategic plan. However, the steering group approach to strategic planning was effective in maintaining the collaborative and consultative approach needed to leverage event benefits across the different aspects of sport and leisure policy. Unfortunately, political, personnel and organisational change and instability since the Games in 2012 meant that much of the momentum for postOlympic legacy was lost. Professionals and agencies in Sport, business, visitor economy, education and health will potentially return to pre-Olympic silos and professional boundaries that the strategic framework helped to cross, without significant post event commitment and the unique appeal of the Olympic Games.
\end{abstract}

\section{Keywords}

Mega-event, legacy, leverage, strategic planning, Olympics, London 2012 


\section{Embracing the games? Leverage and legacy of London 2012 Olympics at the sub-regional level by means of strategic partnerships}

\section{Introduction}

The ability to leverage benefits and establish a legacy from hosting mega events continues to be of significant interest from both academic and policy perspectives. However, relatively few studies have been published in relation to leverage and legacy by cities and regions that are not themselves hosting mega events. This research therefore seeks to add to the evidence base by examining the effectiveness of a sub-regional multi-agency strategic planning process in leveraging benefits from a mega event, the London 2012 Olympics. The paper reviews the literature relevant to leverage and legacy from mega events, the nature of multi-agency partnerships, and the strategic processes found in multiagency working. The key concepts from this literature are employed in the case study to examine the strategic planning process of a sub-regional Steering Group in the North West of England, to achieve the strategic objectives of their legacy framework document, published in 2009. The research was undertaken in a form of knowledge transfer relationship, as the Steering Group sought to benefit from a better understanding of the process of legacy planning and sub-regional working in order to improve the potential to achieve a lasting benefit from what was perceived to be the unique opportunity of a London Games.

Thus, this paper provides an analysis of the effectiveness of a sub-regional multiagency strategic planning process in leveraging from a mega event for community benefits outside of the hosting communities of the Games. Despite the contested nature of the term 'legacy' (Girginov \& Hills, 2009; Preuss, 2007) there has been significant investment in planning for the legacy from the London 2012 Olympics at national, regional and sub-regional level, both in and outside of sport. As Gratton, Dobson, and Shibli (2000) identified, the Olympic-based event benefits are difficult to measure from economic perspectives and the potential for areas outside of the hosing city are even more elusive. In the case of London 2012, clearly the greater benefits for most were expected to be in London and the South East. However, it was evident in all the initial planning and policy development that to justify the significant investment by Government, the London 2012 Games were to provide benefits to communities across the UK (Department for Culture Media and Sport, 2007; 2008a), and across a range of policy areas and measures. Critical to the maximisation of the proposed benefits and legacy from London 2012 was effective collaboration of agencies from different sectors, including health, education, business, culture, the visitor economy, and sport \& physical activity. Effective multi-agency collaboration was identified in plans by Regional and Local Government agencies as being central to the delivery of national Government's legacy promises, and to make opportunities available to the wider UK population outside of London and its environs (Hespe, 2010; Northwest Regional Development Agency, 2009). Such inter and multi-agency working has been a feature of much public sector led 
policy in the UK related to economic or social regeneration, with local government, health, education working with third sector and or business sectors to achieve mutually beneficial outcomes at neighbourhood or community level (Diamond, 2005). Diamond links the need for such collaborations to the relative complexity of the problems being addressed, the limits to capacity of single agencies to address the issues, and the limits to resources. These factors were clearly relevant to the planning for leverage and legacy benefits in the subregions outside of London and the paper examines how such a collaborative approach operated in a sub-region of the North West of England, in the lead up to the London Games in 2012.

\section{Leverage and Legacy of Mega Events}

Leopkey \& Parent (2012b) argue that while hosting of mega events may be viewed positively by the governments supporting the bidding process, the topic of event legacy has a relatively recent history and is the subject of some critical review. The positive economic benefits may only be short-lived (Tien, Lo \& Lin, 2011; Walton, Longo \& Dawson, 2008, DCMS / Strategy Unit, 2002) and evidence of economic benefit is often contested (Crompton, 1995; Crompton, 2006; Pruess, 2008). Although much work has focussed on economic benefits from sport events (Gratton et al., 2000; Gratton, Shibli \& Coleman, 2006; Walton et al., 2008), social and other impacts are also claimed from mega events, such as enhanced community engagement or increased social capital or connectedness, or enhanced national or regional identity (Chalip, 2006; Kellett, Hede \& Chalip, 2008). Increasingly sporting mega-events are recognised as a way of exercising soft power (Grix, 2013; Petersson, 2014) but risk negative outcomes associated with soft disempowerment resulting from increased international scrutiny(Brannagan \& Giulianotti, 2014). However, though non-economic impacts are more difficult to measure (Cornelissen, Bob \& Swart, 2011), combined metrics that provide commensurability, in a triple impact assessment have been applied in tourism (Andersson \& Lundberg, 2013). Furthermore, impacts arising from hosting mega events have been conceptualised in terms of changes to 'soft structures', for example knowledge, networks and culture, and 'hard structures', for example infrastructure and facilities (Preuss, 2007; Gratton and Pruess 2008). However, maximising benefits either in economic or less tangible measures involves the identification and leverage of appropriate assets (Kellett et al., 2008). Chalip (2006) has referred to leverage as a strategic approach to event planning and management which can stimulate not just economic benefits of the event, but can also contribute to social and other agendas, by maximising the benefits of the event to broader communities(Beesley \& Chalip, 2011).

In addition to benefits obtained during the time of the mega event itself, those impacts that extend beyond that period are commonly referred to as the legacy of the event. Unfortunately, there is no agreed definition of legacy in this context (Cornelissen et al., 2011; Girginov, 2011; Girginov \& Hills, 2009; Leopkey \& Parent, 2012b; Preuss, 2007). In practice, most studies and practitioners focus on planned, tangible, positive legacies rather than any unplanned, intangible, negative legacies (Gratton \& Preuss, 2008). Despite a lack of evidence of legacy 
in sport from previous games, there has been significant investment in planning for a participation legacy from the London 2012 Olympics at national, regional and sub-regional level, both in and outside of organised sport (Department for Culture Media and Sport, 2007; 2008a; 2008b). As shown by Weed and colleagues (2009) in the build up to the Games, the mechanisms by which this legacy might be created were poorly understood but thought to be associated with a 'festival' or 'demonstration' effect (Walton et al., 2008; Weed et al., 2012)

Despite the clear intention of the UK Government to spread positive impacts from London 2012 to the regions of the UK, the detailed planning guidance on how to achieve this result was limited, certainly at the time of the awarding of the Games to London in 2005 (Smith, 2009). This may have been because despite the drive to achieve wider benefits, there are few studies on how to achieve them in regions outside host cities (Deccio \& Baloglu, 2002; Smith, 2009). Benefits in the regions would be expected to be intangible, and hence harder to assess, because direct benefits, for example job creation and infrastructure improvement, decline with distance from the host city (Smith, 2009). Expected or planned benefits were from changes to soft rather than hard structures (Preuss, 2007) because investments in infrastructure and logistics are focussed on the host city or region (Cornelissen et al., 2011). Nevertheless, nonhost communities appear willing to pay for the Olympic Games because of perceived benefits that are not directly related to increased participation in sport but because of beneficial impacts on their community or nation(Walton et al., 2008). Thus in developing a legacy for a non-hosting community, engagement with that community that creates a 'festival effect' that is both related to the major event and has relevance for the local community appears to be important to realise benefits (Beesley \& Chalip, 2011; O'Brien, 2006; Weed et al., 2012). This celebration or festival effect is found to be important in the perception of communities of the positive impact of an event (Balduck, Maes \& Buelens, 2011; Chalip, 2006) and is related to a feel-good-factor (Wicker, Prinz et al 2012) or event-related pride (Gibson et al., 2014; Hallmann, Breuer \& Kuhnreich, 2013; Pawlowski, Downward \& Rasciute, 2014) associated with sporting success. Using the event as a background theme and giving emphasis to the celebration aspect in local activities may result in greater participation and ultimately a more sustained legacy in communities (Weed et al., 2012). Smith and Fox (2007) have referred to event-themed rather than event-led legacy planning, around the Commonwealth Games in Manchester, for example, to illustrate this use of cultural and other activities which provided opportunities for community engagement and celebration.

However, while certain beneficial impacts might be expected to occur automatically from the mega event (Smith, 2009) this not necessarily so (Chalip $\&$ Leyns, 2002) and maximising a beneficial leverage and legacy from an event will only be achieved if an effective planning mechanism is in place to leverage that event (Leopkey \& Parent, 2012a; Weed et al., 2012). Customarily partnerships and inter-organisational networks are the apparatus of choice and are seen as important for both economic and social leverage of sport events (Kellett et al., 2008). It might be argued however, that the effectiveness of inter- 
organisational networks in this context have had relatively limited attention in the studies of leverage (Provan \& Milward, 2001). Beesely and Chalip (2011) have indicated potential problems in the transfer of knowledge for event leverage, in particular the dependence of the inter-organisational communication and collaboration needed for effective planning on governance and political structures. Clearly, critical to the maximisation of the legacy from London 2012 was exactly this type of collaboration of agencies from different sectors, including health, education, business, culture, the visitor economy, and sport. Partnership working, bringing together a range of public organisations and other agencies, is a central tenet of modern government in the UK and to promote participation in physical activity in particular (Diamond, 2005; Lindsey, 2009; McDonald, 2005; Phillpots, Grix \& Quarmby, 2011). Effective multi-agency partnerships identified in plans by Regional and Local Government agencies were central to the delivery of national Government's legacy promises of opportunities available to the wider UK population outside of London and its environs (Northwest Regional Development Agency, 2007; 2009).

Membership of a multi-agency partnership represents those who resource or support the partnership, those who work in the partnership, and those intended to benefit from the partnership (Babiak, 2007). Importantly, partnerships of this type form the basis for the establishment and maintenance of a network of salient stakeholders (Mitchell, Agle \& Wood, 1997; Sallent, Palau \& Guia, 2011) and provide mechanisms to elucidate and guide the goals and actions of these stakeholders (Babiak, 2007; Girginov, 2011; O'Brien, 2006). Certain stakeholders may be disinclined to engage with this type of activity, for example small businesses (Chalip \& Leyns, 2002), and active management of stakeholders (Ackermann \& Eden, 2011) may be necessary to support the aims of the partnership. In practice, the fundamental assumption in multi-agency collaboration, that there are advantages to working collaboratively over working as individual organisations, is hard to realise (Cairns \& Harris, 2011; Huxham \& Vangen, 2004). Working in this way is challenging (Babiak, 2007; Phillpots et al., 2011), in particular the demands of interdependence require a high degree of coordination and communication (Emery, 2010; Parent, Rouillard \& Leopkey, 2011).

It has been proposed that an effective mechanism to address these challenges is a strategic planning approach (Emery, 2010), ensuring that an appropriate set of outcomes are incorporated into that plan (Chalip, 2006). Although strategic planning has become somewhat discredited (Mintzberg, 1994), and a diversity of approaches to strategy described (Mintzberg \& Lampel, 1999; Whittington, 2001), strategic planning continues to have significance for practitioners (Whittington \& Cailluet, 2008). Indeed, it has been argued that a clear vision and effective planning process are more significant factors in the success of a partnership than funding, because without a clear vision and effective process, funding would not be effectively utilised (Kellett et al., 2008). What appears to be adopted in practice is an approach to strategy that incorporates some of the benefits of strategic planning but retains more flexibility than a fully prescribed sequential planned strategy (Bramwell, 1997; Stokes, 2006). 
However, the planning undertaken by a sub-regional partnership will not be completely voluntarist because the partnership will be subject to institutionalising and other forces from the International Olympic Committee (IOC), the relevant Organising Committee of the Olympic Games (OCOG) and other stakeholders (Leopkey \& Parent, 2012a; Whittington, 1988). Even with an emphasis on collaboration and partnerships in relation to sport (Babiak, 2007), it has been argued that centralised control of sport has increased (Phillpots et al., 2011) and hierarchical relationships and structures are still important (Goodwin \& Grix, 2011), particularly within governmental agencies. In order to gain access to resources, for example branding, intellectual property and funding, held by powerful organisations such as IOC and OCOG, sub-regional partnerships have to engage with these relationships and structures (Smith, 2009). These relationships and structures therefore not only present constraints but also provide access to resources (Whittington, 1988). This can cause tensions between what counts as legitimate behaviour for the partnership and for a member's host organisation (Huxham \& Vangen, 2004), and the extent that an individual identifies with the partnership or their host organisation (Dutton, Dukerich \& Harquail, 1994).

The extent of identification with the partnership by members can be an important consideration in the success of the partnership. Membership can be to some degree voluntary, especially where the remit of the partnership is outside the core responsibilities member's host organisation. Notwithstanding the professionalism of individuals, under circumstances of competing demands, partnership involvement is likely to be sacrificed in order to meet more fundamental responsibilities in the host organisation. This is particularly important because individuals in either coordinating (Smith \& Fox, 2007) or leadership (Vangen \& Huxham, 2003) roles can make significant impact on the success of partnerships. Individual interests and relationships are important in partnerships (Frisby, Thibault \& Kikulis, 2004; Hutt, Stafford, Walker \& Reingen, 2000) and this understanding adds complexity to purely economic or strategic theory based interpretations of partnerships (Babiak, 2007). Although partnerships will have stability because they are based on inter-organisational and not just personal relationships (Stokes, 2006), accepting the importance of the role of individuals in partnerships leads to the conclusion that the ability to attract capable and motivated members can be a critical factor in the success of a partnership (Emery, 2010; Ferkins \& Shilbury, 2012).

A significant challenge often arises in the agreement of purpose and goals for the partnership. While it is argued that partnerships should establish key goals and metrics around the purpose of the partnership and the sustainability of the network (Babiak, 2009), the diversity of individual and organisational interests represented in the partnership makes clarity of this type difficult to achieve in practice (Huxham \& Vangen, 2004; Vangen \& Huxham, 2012). While for some members, the purpose of the partnership will be central to the goals of their host organisation, for others this purpose is incidental to the goals of their organisations or even their personal goals (Huxham \& Vangen, 2004). Given the diversity of members in a partnership and their various organisational and 
individual goals, often action is taken to move the partnership forward without full agreement on the goals of the partnership (Huxham \& Vangen, 2004). Clearly, this is in contrast with the recommendation that for success a clear vision is important (Kellett et al., 2008).

This contrast highlights some of the limitations in applying certain of the mainstream strategy and management concepts to multi-agency partnerships formed for leverage and legacy of mega events. There is of an inherent contradiction between concepts such as long-term vision (Collins \& Porras, 1996) and strategic planning (Grant, 2003) and the short-term and temporary nature of partnerships developed to address event legacy (Smith \& Fox, 2007). With regard to the London 2012 Olympic Games the lifetime of organising committees is significantly shorter than the timescale needed for an appropriate evaluation of the legacy from the games, leading to a lack of clarity over who is responsible for the delivery of this legacy (Leopkey \& Parent, 2012b). In a sub-regional context a partnership whose purpose is to deliver a legacy is faced with a similar issue regarding the lifetime of the partnership and the timescale of the legacy. These partnerships are typically described as having phases of planning, implementation and wrap-up (Parent, 2008; 2010) or antecedents, management and evaluation (Parent \& Harvey, 2009), implying a finite lifetime in contrast with the assumptions of longevity in the mainstream management literature. Further insight into the effective operation of these short-lived partnerships might be gained from the temporary organisational literature (Bakker, 2010) or the emergency planning literature (Bigley \& Roberts, 2001). One aspect that has not been widely studied is the formation of enduring relationships and networks that extend beyond a single event and its legacy but can be a basis for taking advantage of future opportunities (O'Brien, 2006).

\section{Sub-regional leverage and legacy planning in Cheshire}

At the time of planning for the post-Olympic Legacy, there had been no specific 'blueprint' for legacy outside of the hosting communities. This deficiency was exacerbated by the uncertainty associated with the costs of the event associated with a systematic tendency to underestimate the costs of large scale projects (Jennings, 2012). Indeed even within the London Boroughs, this potential for legacy was an unknown quantity and costs were of concern (Kornblatt, 2006). Despite the Government's commitment to spreading the benefits of the Games to all parts of the UK, there were also concerns that the bulk of investment was being focused in London, though costs would be borne across the regions (Department for Culture Media and Sport, 2007; 2008a; b). Regional plans for legacy, developed by the Regional Economic Development agency (Northwest Regional Development Agency, 2007; 2009) had been important in framing the planning of Cheshire's opportunities and helped to stimulate and focus attention of key agencies. To leverage benefits and deliver a legacy from the London 2012 Games in Cheshire a multi-agency steering group was established. In 2007, the steering group set out an ambitious strategy to achieve its mission for 2012 , incorporating cross-sectoral interest groups, diverse organisation types across Cheshire and engaging with National and Regional legacy planning across sport, 
culture, business, and the visitor economy. With the support of an external consultant, resourced by the partnership the 'Embrace the Games' Legacy Framework document, was produced that brought together aims, objectives and strategic directions for use by other organisations and agencies, to stimulate planning and activity and provide a shared vision for legacy.

The document, developed through extensive consultation across sectors and partners made reference to regional and national plans, framed by sub-regional priorities. The vision provided in the Framework was:

'For Cheshire \& Warrington to secure a lasting and beneficial legacy from the 2012 Olympic Games and Paralympic Games by individuals and communities embracing high quality sport and physical activity, art and culture, tourism and business opportunities which change lives and society for the better.' ( Cheshire Embrace the Games Steering Group, 2008: 4)

The Framework was structured around the key themes of Cultural Olympiad, Sport and Physical Activity, Visitor Economy and Business Opportunities, underpinned by principles of increasing volunteering, and skills acquisition, the provision of sporting and cultural events and enhancing health and well-being in communities. There were four identified 'champions' from within the steering group, in Volunteering, Visitor Economy, Sports and Cultural sectors. The work of the steering group was supported by financial and other resource contributions from the Local Authorities and other agencies in the steering group, such as Marketing Cheshire and Sport Cheshire, with their own particular expertise and organisational inputs. The steering group for the framework and strategic planning was therefore made up of representative from Local Authorities, Marketing Cheshire, Sport Cheshire, North-West Regional 2012 (later Nations and Regions 2012), Chamber of Commerce, Education (including Higher and Further education) and Cultural Bodies as occasional contributors and representing wider stakeholders. Although Children's Services, Health and Cultural representatives were not always evident in the group planning documents or minutes, they were consulted or invited to contribute. The steering group organised and coordinated the plans for a series of events to promote the Games opportunities and programmes relating to the Legacy, for example, the Inspired by 2012 accreditation for specific projects, or Get Set, the educational resource for schools. They also organised a series of business events and workshops and coordinated plans for the Torch Relay and other cultural events across the subregion, in order to engage businesses, community groups and the wider community in legacy-themed activities.

In 2012 the steering group commissioned the researchers to undertake an investigation into their planning and processes in relation to London 2012 legacy in order to determine whether these had realised the expected benefits identified in the 'Embrace the Games' Framework. This represented an opportunity to develop some knowledge transfer between the organisations with wider dissemination of the results of the research, as well as contribute to the evaluation of event impacts for LOCOG and the Nations and Regions group. It was considered that understanding what was achieved in terms of legacy 
planning in a particular sub-region (in this case Cheshire) would be of interest not just within the sub-region, but more widely and for other events to be hosted nationally and regionally in the forthcoming 'Decade of Sport' announced by DCMS in the UK(Robertson, 2012).

\section{Methodology}

In order to examine the effectiveness of a sub-regional multi-agency strategic planning process in leveraging benefits from the London 2012 Olympics a case study methodology (Yin, 2003) was adopted. This approach was considered appropriate as the intention was to understand factors at play in a single setting (Eisenhardt, 1989). Pragmatically this choice was influenced by the commissioners of the research, the steering group of the partnership under study, who requested an evaluation of their strategic planning process. This did to some extent constrain the choice of research methodology but had the advantage of securing comprehensive access to documents, records of the events and key informants, the steering group members and partners. This approach is valid because, as identified in the literature review, studies of legacy in regions outside host cities are rare and hence this is a case study of intrinsic value (Stake, 1995). A qualitative, interpretative approach to complex and diverse data sources and their analysis was undertaken.

The study commenced in June 2012, immediately before the start of the London 2012 Games. Primary data collection chiefly occurred in June and August 2012, with additional observations and document analysis covering May-September, relating to pre-event and Paralympic-based activities. These dates have a number of consequences for the research process and the conclusions drawn from the research. The research questions and methods were limited to those which could be conducted in the narrow timescale available, of June-August 2012 for primary data collection. As the researchers were not involved at the initial stages of partnership formation and planning, data relating to these stages had to be obtained retrospectively from archival documents and key informants. While acknowledging this limitation, obtaining data from more than one source improved reliability via data triangulation (Jick, 1979). Additionally, the research was completed before legacies from the event would be fully realised and so detailed analysis of outputs, activities or data relating to specific legacy themes was beyond the scope of this study. Hence the emphasis of the research is on the experiences of the members of the steering group regarding the effectiveness of the partnership rather than specific assessments of cost/benefit or other legacy outcomes. A draft report was presented and discussed with the steering group in October 2012. This met not only the commissioners' needs for a pragmatic evaluation of steering group's activities but also the researchers' needs for respondent validation. Following comments from the steering group on the draft report, the final report evaluating the steering group's effectiveness in achieving leverage and legacy was presented to the steering group in November 2012. It was beyond the scope of this study to complete a full analysis of the outcomes of the planning process across all of the framework action plans or to engage with a wider network of stakeholders in the planning process. 
Three sources provided the data for the case study: semi-structured interviews with key informants $(n=10)$ who were partnership members or other stakeholders; documentary analysis of public and internal documents covering the period 2007-2012, including agendas and minutes of steering group meetings, analysis of commissioned reports and planning documents; and observation of events and activities coordinated by the steering group and others in the sub-region in the period from $2009-2012^{1}$. The focus of the research was pre-Olympic planning in the lead up to the Games in London and the views of stakeholders of the effectiveness of the process of legacy planning and operation of the steering group. Following interviews, respondent validation of the transcripts and in an initial draft report was used to confirm both accuracy and interpretations and to improve clarification where necessary. This was important to validate the interpretation of interview data and the themes derived via inductive thematic analysis. In the interviews respondents were encouraged to reflect on and provide their own narrative of their experiences, personal and organisational perspectives of the process and what it had achieved.

Contributions were anonymous in the report, and in this paper, to encourage a more open dialogue and as individuals were providing personal views in a professional context, it would not be possible to completely anonymise the respondents. Thus it was possible to develop a much richer understanding of the planning process they had engaged in and how different individuals and organisations conceptualised and operationalized 'legacy' and the experiences of the activities of the steering group as a process of leverage.

After initial findings were shared with the steering group lead and members, a final report was produced for dissemination between the partner agencies. This report also included recommended actions for activities and planning, both for on-going London 2012 based projects in the sub-region and to take advantage of what had been learnt from this experience. This was referred to in the final evaluation report of the Nations and Regions group (NW Nations and Regions, 2012) as further validation of the relevance of the findings for future planning. This research paper is developed with permission from the final report, through additional analysis of the interview transcripts and other documentary material in the light of the literature and additional reflection on post event impacts,.

\section{Data collection and Analysis}

\section{An initial meeting with the Chair of the steering group established the parameters for the study, the timeframe for the work and the key informants for}

1 One of the researchers had taken part in various activities noted thus observational memos and reflections on participation in the activities were incorporated into the analysis of other data. As a source of triangulation this also provided some greater insight into public and other responses to the Olympic themed activities, such as Torch Relay, and the cultural events in the summer of 2012. 
interview representing the members of the partnership. The key informants were from partner organisations in the steering group including each of the three local Authorities, the County Sport Partnership, and Education sector organisations including Higher, Further and Secondary Education. A consultant employed by the steering group was a key individual in the development of the strategy document, and a representative of the Nations and Regions group (formerly part of the Regional Development Agency) provided a perspective of regional governmental and LOCOG planning. Unfortunately, the Chamber of Commerce representative was unable to co-operate with the study, due to changes of personnel and the time constraints for data collection. This is illustrative of the suggestion that it is difficult to engage small businesses in activities to leverage economic benefits from sport events (Chalip \& Leyns, 2002).

The interviews lasted from 40 minutes to 120 minutes, and were recorded and then transcribed verbatim for later analysis. Transcripts were returned to respondents for checking for accuracy and to allow them to make any additional observations or comments relevant to the study objectives, prior to the thematic analysis. Broad themes from the strategic management literature were employed as initial orienting concepts to guide the semi-structured interviews. The intention in using these themes was to orientate the respondent to provide relevant data but not to constrain their responses by an overly developed conceptual framework; to utilise sensitising rather than definitive concepts (Blumer, 1954). Subsequent analysis of interview data followed an inductive approach (Eisenhardt, 1989) to identify key themes relating to the effectiveness of the strategic planning and other processes to achieve the desired legacy framework outcomes, and relating to the different perspectives of public sector bodies, commercial organisations, educational partners and stakeholders.

The qualitative data analysis software NVIVO was utilised to help organise the various forms and sources of data, and to enable comparison of independent analyses of the data set by the two researchers. Initial codes were generated in the inductive analysis which were then grouped under themes, relating to the process and management of the 'Embracing the Games' framework. Transcripts were coded via text search on related words or concepts, on semi-structured responses, and grouped under specific codes or nodes that emerged in responses, into themes. The authors worked independently initially, subsequently merging the nodes, cross checking for consistency as themes emerged and their implications were considered against the literature to develop a more rounded review of the multi-agency strategic planning process. Themes were discussed in the light of the literature above. This approach is not purely inductive 'grounded theory' (Glaser \& Strauss, 1967; Strauss \& Corbin, 1998) but makes use of prior theoretical concepts (Siggelkow, 2007; Yin, 2003) to develop the explanations or processes and inductive analysis within the identified themes. Content analysis of documents, notes and memos also used a thematic approach.

\section{Stakeholder Perspectives of 'Embracing the Games' in Cheshire}


The key themes are presented here in summary with anonymous illustrative quotes where relevant. The themes are expanded upon by identifying the various sub-themes that emerged as nodes in the thematic analysis and then developed in the discussion.

The key themes were:

- $\quad$ The aspirations and objectives of the steering group and to what extent these have been realised

- $\quad$ The drivers, enablers, barriers and challenges faced by steering group partners

- The actions and decisions taken, the processes and structures used by the steering group

- The mechanisms for planning, guiding and evaluating the steering group

- $\quad$ Specific changes in policy and practice, or 'lessons learned' by the steering group.

The specific questions or interview schedule derived from these themes can be found in appendix 1 .

\section{Aspirations and Objectives- shared purpose and a commitment to Olympic benefits}

There was a strong consensus among the respondents about the objectives and purpose of the group, which was consistent with the framework document. This relied very heavily on the connectedness of the group, their objectives and the objectives of the constituent bodies and organisations.

'once the right group of individuals came together, they did have, you know, a very similar view in terms of what they were wanting to achieve and how they could go about achieving some of the objectives'

The initial aspiration of working together to jointly achieve objectives was perceived as successful, but without clear hard measures of success being identified in the framework document. The notion of ' $f i t$ ' emerged as an important concept, where the group's objectives aligned with the partner organisation's objectives. Not surprisingly there was a strong alignment within the steering group to public sector, welfare and social objectives. There were however tensions expressed between the organisational objectives and steering group role, for example:

'the difficult bit of it is that you go in there as a co-ordinator representing the [home organisation], you've then got to come back here and get the buy-in from everybody back here'

'a critical tension between being part of a collective and going back and saying, my day job and my requirement for [host organisation]' 
However, the 'fit' with the corporate objectives was seen as essential particularly by the Local Authorities - but also the Education sector representatives:

'that wouldn't have happened unless we at a local level had decided that was one of our key priorities, it hit one of our corporate objectives'

The notion of 'fit' or alignment also emerged with national, regional and subregional plans and structures. There had been clear alignment to Regional economic and Legacy objectives and the North West steering group. This was thus related to the relative success of the steering group in achieving their objectives and those of the partners and in engaging local decision makers in legacy-related activities or leverage.

\section{Drivers and Enablers in the planning process- Communications and Key individuals}

A number of drivers and enablers were identified by interviewees as contributing to effective operation of the steering group. As noted above the consistency of objectives and consensus were considered important to maintain focus despite changes and over time and maintain momentum. Communications, within the group, with the public (mainly via the website and local networks, achieving national publicity) and with external groups were important in achieving objectives. However, external communications emerged as an area for improvement as a website was developed relatively late in the process and there were mixed views of its effectiveness for public awareness of legacy activities and for communications between partner organisations.

'it's maybe probably around communications that things started to creak a bit... we didn't probably have the mechanisms to connect the communications more effectively'

'We got the Embrace the Games website eventually. Probably we should have done an Embrace the Games website right at the start with a central port and what is it, and populated that much earlier'

Influential individuals were considered to play important roles in the success of the steering group. For example the Chair of the steering group and the representative of London 2012 Nations and Regions group were identified as being influential in alignment with national and regional structures and maintaining the focus on agreed objectives. Having individuals with the commitment, drive, passion, vision, and leadership skills was seen as important to success within the Embrace the Games group, but also as individuals involved in the group had to be able to influence their own organisation, leading as 'legacy champions' or acting as a leader for legacy related activity.. The importance of a designated individual to coordinate and administer the operation of the steering group was also highlighted, but was also referred to as a potential weakness, when resources were no longer available prior to the Games to support a designated post for the co-ordination of legacy efforts by the various 
'champions'. Other individual roles were affected by changes in policies and governance structures in the region after the change of Government in 2010. Many respondents highlighted the importance of individuals both for achievement of the framework objectives and of the influence in the partner organisations:

'it's about individuals who chose to seize the moment, and individuals who have chosen not to'

\section{Hindrances or barriers to achieving objectives - Change and moving goalposts}

There were some areas noted as particular challenges and these were fairly consistent across the interviewees, both external to the group and affecting their own organisations. Some of these related to changing political structures in local and regional organisations and changing political priorities:

'It was a challenge against the backdrop, certainly for us, of local government review'

The economic climate presented specific challenges:

'some of the aspirations that we had at the beginning when we started out were set out when the economic situation was different'.

Other hindrances related to the operation and representation of the steering group itself in terms of the inclusion of the right balance of representation to achieve aspirations:

'one of the main challenges for them was to get the right individuals together'

A degree of role ambiguity resulted in some lack of understanding or confusion over resources and responsibilities, for example, if individuals were acting as representatives of LOCOG, DCMS or Nations and Regions. Relationships with the event organiser (LOCOG) were a source of major concerns for Local Authorities, in particular about the extent of LOCOG transparency and assistance with subregional planning. This issue had been highlighted by Smith( 2009) as potential problem with leverage of social impacts. Concerns were expressed over branding restrictions, which limited benefits to business and the promotion of activities.

Concerns were also expressed over the close control and restricted communication by LOCOG over the Torch Relay, Games Maker recruitment, Paralympic events and ticket allocation, which the Nations and Regions representatives had to manage. This had appeared to limit the autonomy of the stakeholders to fully 'leverage' the expected benefits and to plan effectively and could have contributed to the negative perceptions of LOCOG relationships.

Perhaps unsurprisingly resources were seen as problematic by most respondents - mainly due to the economic pressures indicated above that resulted in resource scarcity, that is, not enough resource had been available at local level, or resources were allocated late, or not clearly dedicated to legacy-themed activity. Planning had been effected by uncertainty of resources and their source, 
particularly after 2010 and the Games were closer but budgetary controls tighter. For example, the Education sector representatives were critical of the lack of resources to support the legacy aspirations around the Paralympic Torch event, compared with the more visible and media-friendly Torch Relay events in Cheshire. In order to support the legacy aspirations organisations had to find resources to pay LOCOG or other agencies, for Mascots to appear at events, or for official 'sporting Champions'.

Lack of engagement with certain stakeholders was considered to have hindered the achievement of objectives, particularly with Health-related partners and agencies responsible for Children and Family services in the sub-region. The business community was seen as insufficiently engaged with many of the action plans, which were more oriented towards social rather than commercial opportunities. Furthermore, the variability in decision making processes between partners with different decision-making and planning time frames lead to a degree of misalignment of actions to support the partnership, even though there was consistency or support in their plans. Interviews and documents illustrated the inconsistency of contribution and influence of the framework into the wider policy sectors. There was considerable variation between the different interest groups in how they engaged with and integrated legacy into their planning.

\section{Operation of the steering group}

The Steering Group reliance on quarterly (or less frequent) face to face meetings of the nominated partners was perceived by some as being resource heavy but by others as a good way to achieve communications with people. As Diamond(2005) suggested, the nature of this cross sectoral work means such relationship building and collaborative working can be resource and time intensive. Attendance at meetings was indicative of engagement and contribution to decision making, not merely reporting activity, but indicative also of the importance the partner organisation attached to the work of the steering group. Various respondents indicated that meetings would have been more effective if they had been less reactive, with increased communication in follow up, with monitoring data presented in advance of the meeting and planning information shared more consistently. However it was recognised that this would have taken considerably more resource than had been made available to support the group by the partner bodies. The face to face meeting approach was perceived as being helpful in breaking down sectorial boundaries but may also have hindered some greater engagement by the health sector for example, or the strategic level of Education, who had not been identified as 'leads' or 'champions' for legacy in their own organisations. There was also a clear delay in actioning and reporting meeting outcomes, which became more problematic as the Games approached and more pressing operational concerns occupied those responsible for legacy-related projects and activities.

\section{Activities and achievements: Leverage in the Partnership}

Perhaps unsurprisingly, all respondents thought the main objectives of leveraging benefits to the communities across Cheshire via the Embrace the 
Games steering group and Framework were achieved, given the economic climate and changes to the public sector noted above. Activities that were consistently described as successful across respondents were: sport related activities, the Torch relay, Pre-Games Training Camp events, and Conferences to promote legacy planning (in 2010 and 2011). Again, this is perhaps unsurprising as those were key to the framework aspirations and where most of the steering group activity focused. Most interviewees noted that the events (Conferences and Torch Relay specifically) were a positive feature of the sub-region's activities; successful, well organised, collaborations, that had clearly brought significant attention or profile to the sub-region and successfully engaged its communities. The conferences for organisations involved across Cheshire, were noted as being good for dissemination and marketing of the Embrace the Games activities and promoting the full range of Olympic related activities to the community and key decision-makers. One possible criticism was that events were arguably attractive to the already converted and engaged in legacy-themed activity, though the meeting minutes referred to very positive feedback. Events in the build up to the Games provided, as had been anticipated, a showcase of activity, but had arguably limited public profile outside the stakeholders and partners. There was some debate also, in that the high numbers attending the celebrations or torch relays in advance of the Games were not in themselves evidence of any future legacy, but indicative of the high level of public interest in the Olympics.

Those described as less successful were: cultural events, the impact of the 'Inspired by 2012 ' branded projects, or benefits to businesses. This may be related in some part to the difficulties in assessing the degree of success of these types of activities. One specific cultural Olympiad event, 'The Moment When' was prominent in the data. 'The Moment When' was a year-long programme of dance related activities culminating in three outdoor performances at different venues across the sub region (Ainsley and Corkery, 2012). This was a large, externally funded cultural community dance activity combining professional and community performers supported by the Cultural Olympiad, Arts Council and Local Authorities. Disparate views were expressed on the extent to which this was a 'success' of the Framework. For some respondents 'The Moment When' attracted significant media coverage, improved the profile of the region and was well received by audiences. For other respondents it was an expensive drain on limited resources, had limited public exposure (due to the ticketed nature of the performances) and appealed to a narrow group of participants. One respondent indicated some of the reservations about the wider impact, though was apparently unaware that the event had engaged considerable community activity in the preparation for the three public performances, which had included large crowds (25,000 tickets distributed) at Chester for the Torch Relay celebration. Another of the informants, unaware of the community dance project underpinning the performance suggested:

'they're one-off events, and for me to engage cultural initiatives, it would have been far better to use that money now in hindsight, to use Cheshire Dance to go and work with, you know, schools, communities, and actually get the culture out into those key areas, rather than doing these wonderful displays' 
The subsequent report on the evaluation of the event demonstrated that the perceptions of the partners were perhaps based on a lack of understanding of the scale of the participants and professionals involved or lack of awareness of the report commissioned to monitor and evaluate this process in social, cultural and economic impacts (Ainsley \& Corkery, 2012).

At the time of the interviews, there was a lack of empirical data available underpinning the perceptions of 'success' and due to the limited research (with the exception of small studies of Pre Games Training Camps and 'the Moment when' noted above). For increases in sport participation the Local Authority partners were relying on the Active People survey data from Sport England to pick up any population level increases in activity, and the self-reports of participation numbers on funded sport programmes. Clearly this raises the overall question of how 'success' of the Embrace the Games planning can be measured as there are differences in perceptions or lack of clarity on the indicators of success. Concerns that large crowds to celebrations such as the Torch Relay were not necessarily going to leave any lasting impact on the subregion were expressed by several respondents, despite them providing celebratory opportunity for local residents to become part of the Olympic experience. As noted by Chalip (2006) such celebrations made significant impacts on communitas and a sense of being part of the major cultural and social phenomenon of the Olympic Games. However, converting this 'celebration' to a measurable benefit for local economy was difficult:

'the visit of the torch relay, yes, we got 42,000 people on the street. Did it have any impact on the economy? Difficult to tell...'

\section{The lessons learned on leverage and legacy planning}

The initial aspiration of working together to jointly achieve objectives in the planning for a Games legacy in the sub-region was perceived as successful, but without clear hard measures of success being identified in the document or developed subsequently, the leverage of benefits from London 2012 into the subregion is difficult to assess. Therefore though this strategic approach to leverage might be successful in the future, or in other areas, locally derived measures of success or achievement against which evaluate plans must be devised. Clearly also, the Olympic and Paralympic activities had a unique and distinct appeal, and though future events like the Commonwealth Games or Rugby World Cup were in the planning horizon, they were unlikely to attract either the attention or resources achieved in 2012, so partners were not apparently planning to continue with the Steering Group, even during the summer of 2012, despite their positive views of its effectiveness.

The Steering Group approach to the leverage of benefits, using the Embrace the Games framework largely achieved its objectives with regard to sport \& physical activity (within the timeframe of the study) in the build-up to the Games in London. The Games had a significant impact on sport organisations and services that were able to engage with a range of sport or Physical Activity initiatives in the subregion. However, impacts were difficult to attribute to any specific actions 
of the Steering Group, but rather the framework might have provided some stimulus to the planning and the specific events of Embrace the Games highlighted potential benefits of community engagement. However, the different perceptions of cultural activity and its impact reflected some of the difficulties in assessing legacy outcomes (Cornelissen et al., 2011).

The benefits to the visitor economy and business are less obvious, primarily because of a lack of data, from either analysis or respondents. For business, success in leveraging the asset of an Olympic 2012 branding incorporates restrictions on the publication of that success, as had been found by Kellett, Hede et al. (2008). Consequently though undoubtably some sub-regional businesses gained from their association or support of the London 2012 Games, it was likely to be the National 'partners' with the greater profile who were more able to leverage the greater benefits.

A number of factors supported the success of the Embrace the Games partnership as a strategic planning group. The ability to connect and maintain relationships with national and regional structures was important as this legitimised the activities of the partnership (Goodwin \& Grix, 2011; Smith, 2009) and facilitated access to resources (Whittington, 1988). There was some concern over role ambiguity and relationships with LOCOG, indicating the importance of relationships with the event organisers. Although external communication was an area for improvement, the partnership appears to have sufficiently addressed the challenge of communication and coordination within the steering group, consistent with the good practice highlighted in the literature on events and strategic approaches to leverage(Emery, 2010; Leopkey and Parent 2012b). As in previous work on partnership and around events, the role of individuals with influence and enthusiasm was very important in both leadership (Vangen \& Huxham, 2003) and coordinating roles (Smith \& Fox, 2007). The alignment of goals of the partnership with those of the individual agencies and a degree of consistency and consensus contributed to the success of the partnership, although there was some evidence of moving forward to maintain momentum without complete clarity of goal (Huxham \& Vangen, 2004). Finally, the use of specific local events to raise the profile and reputation of the region with residents and visitors was considered to be effective. Interestingly a 'festival effect' (Weed et al., 2012) was demonstrated through culturally orientated events, particularly those related to the Torch Relay celebrations. However, as pointed out by the Nation and Regions representative, whether or not individual partners or others benefited from the Embracing the Games Framework was largely due to their perspective of the Games as a strategic opportunity:

'is about trying to recognise how London 2012 could help them achieve their existing objectives. It wasn't all about new stuff but actually how can the Games or can the Games help them to achieve what they're already trying to achieve; better, smarter, bigger, etc. Those that really grasped that you found were able to really hit the ground running. For others, it was a long battle about well, what's it going to do for us? ' 
Clearly some activities were more successful or perceived to be more beneficial than others in leverage of benefits to local communities or organisations. Public Sector partners appeared to be committed to drive the use of Leisure, Culture and Sport to achieve wider social objectives from London 2012, but due to economic and other constraints, this was clearly more difficult to sustain after the Olympic and central 'legacy-based' structures had been dismantled. While cross sector and multi-agency work related to the Olympics had a clear and unifying 'raison d'etre' in the lead up to July 2012, this was far from clear by the end of 2012, as attention was being drawn to future events and the planning horizon moved to the next 4 year cycle. However, in Cheshire there had been limited interest even by the Autumn of 2012 in maintaining a cross sectorial approach to planning around future events. The Olympics had clearly been identified as having a unique appeal and key to gaining cross sectoral support for such long term and strategic planning. In the preparation for the Rugby League World Cup in 2013 however, there was a focus by the event organisers on the areas hosting games with little co-ordination across into other parts of the subregion and involving a more narrow and focused approach to leverage. Thus, the cross - sectoral partnership approach became less effective after the 2012 Games and for subsequent events, less evident, despite the positive messages in the final report on the 'Embracing the Games' framework and clear recommendations which supported this approach for future planning. One proposal to the steering group based on the research was that core membership of the Steering group was maintained, reflecting the interests of partners, to identify and evaluate potential future events that might be leveraged in a similar way to London 2012, albeit on perhaps not the same scale. However, this recommendation was not followed up by the partnership.

\section{Conclusions and implications}

The inter-organisational partnership approach to strategic planning for event leverage and legacy experienced significant difficulties arising from the external environment, principally the austere economic environment and the extensive structural changes for the public sector over the time frame leading to the event. These to some extent resulted in exacerbated resource scarcity at precisely the time when more resources were needed to convert potential for legacy into more concrete actions. Many partners were limited in their ability to deliver the aspirations or fully leverage the benefits set out in the strategic plan.

Communication, while considered adequate, could have been improved and this might have helped with a lack of engagement from certain stakeholders. A more proactive stakeholder management approach (Ackermann \& Eden, 2011) might have increased the involvement of stakeholders, though this clearly required dedicated resources to maintain. Improved communications might also have improved the view of some respondents of the effectiveness of face to face meetings which were the principle mechanism for coordinating the steering group, but were difficult to maintain 
There are clear implications from this case study for the extension of any broader legacy from the mega-event beyond the hosting city and planning for leverage of benefits. This study may be seen to contribute particularly to better understanding of the problems of the leverage of benefits outside hosting communities and across sectors. In this sub-region as with others, the political, personnel, organisational changes and instability since the Games in 2012 has meant that much of the momentum for post-Olympic legacy has been lost, without a leading organisation for the work, or specific resource allocation. Professionals and agencies across the Sport, education, visitor economy and health sectors will potentially return to pre-Olympic silos and professional boundaries which the strategic framework helped to cross, without specific action to address this problem and a clear unifying purpose. Thus though a steering group approach to strategic planning has been shown to be useful and effective in maintaining the collaborative and consultative approach needed to leverage event benefits outside of the hosting city, unfortunately without the organisational 'glue' provided by the Olympic Games this relationship has not been sustainable after the event has taken place.

Finally, the case study illustrates that any legacy whether tangible or not, established in the pre-event phase should be well established by those engaged in economic, social or public policy strategic planning in order to reap the benefits as well as ameliorate the perceived costs of the mega event in the regions beyond the host communities. Clearly, even 'soft' or intangible legacy has costs for the organisations in sub-regions in terms of human and financial resources to leverage benefits. National policy makers and event organisers must therefore anticipate and account for such costs in their planning and support this process to maximise event impacts in the regions. Olympic events have a unique, cyclical and clearly defined geographic focus mainly on the hosting city. However, this case has illustrated that local stakeholders in more peripheral areas can be engaged in planning and leverage activity at a strategic level, where a potential for legacy benefits can be identified. With sufficient planning time and an appropriate forum, it is possible to create useful local frameworks and partnerships for achieving leverage from mega events which local populations can 'embrace'. 


\section{Appendix 1 Interview questions}

1. Goals

a. What were the objectives of Embracing the Games?

b. To what extent would you say these objectives have been achieved?

c. Who are the key stakeholders?

2. Actions

a. What actions taken were most effective in pursuit of Embracing the Games objectives?

b. What actions taken were least effective in pursuit of Embracing the Games objectives?

c. How was the strategy process managed?

3. Issues

a. What factors supported the achievement of Embracing the Games objectives?

b. What factors hindered the achievement of Embracing the Games objectives?

4. Performance

a. What measures were used to assess progress towards Embracing the Games objectives?

5. Review and learning

a. In what ways do you think the strategy process could have been improved?

b. Faced with a similar situation what would you do differently?

c. Are there any other comments you would like to make in relation to Embracing the Games?

\section{References}

Ackermann, F., \& Eden, C. (2011) Strategic management of stakeholders: Theory and practice. Long Range Planning, 44 , 179-196.

Ainsley, M. \& Corkery, H. (2012, January 25 2013). The Moment when.. Evaluation Report. Chester: Cheshire Dance. Retreived from: htpp//www.cheshiredance.org/2012/TMWEvalFINAL.pdf

Andersson, T. D., \& Lundberg, E. (2013). Commensurability and sustainability: Triple impact assessments of a tourism event. Tourism Management, 37, 99-109. 
Babiak, K. (2007). Determinants of interorganizational relationships: The case of a Canadian Nonprofit Sport Organization. Journal of Sport Management, 21, 338-376.

Babiak, K. M. (2009). Criteria of effectiveness in multiple cross-sectoral interorganizational relationships. Evaluation and Program Planning, 32, 112.

Bakker, R. M. (2010). Taking Stock of Temporary Organizational Forms: A Systematic Review and Research Agenda. International Journal of Management Reviews, 12, 466-486.

Balduck, A. L., Maes, M., \& Buelens, M. (2011). The Social Impact of the Tour de France: Comparisons of Residents' Pre- and Post-event Perceptions.' European Sport Management Quarterly, 11, 91-113.

Beesley, L. G., \& Chalip, L. (2011). Seeking (and not seeking) to leverage megasport events in non-host destinations: The case of Shanghai and the Beijing Olympics.' Journal of Sport \& Tourism, 16, 323-344.

Bigley, G. A., \& Roberts, K. H. (2001). The incident command system: Highreliability organizing for complex and volatile task environments. Academy of Management Journal, 44, 1281-1299.

Blumer, H. (1954). What is wrong with social theory? American Sociological Review, 19, 3-10.

Bramwell, B. (1997). Strategic planning before and after a mega-event. Tourism Management, 18 (3), 167-176.

Brannagan, P. M., \& Giulianotti, R. (2014). Soft power and soft disempowerment: Qatar, global sport and football's 2022 World Cup finals. Leisure Studies, advance online publication, 1-17. DOI:10.1080/02614367.2014.964291

Cairns, B., \& Harris, M. (2011). Local Cross-Sector Partnerships Tackling the Challenges Collaboratively. Nonprofit Management \& Leadership, 21, 311324.

Chalip, J., \& Leyns, A. (2002). Local business leveraging of a sport event: Managing an event for economic benefit. Journal of Sport Management, $16,132-158$.

Chalip, L. (2006). Towards Social Leverage of Sport Events. Journal of Sport \& Tourism, 11, 109-127.

Cheshire and Warrington 2012 Steering Group (2008). Embrace the Games Cheshire and Warrington Legacy Framework for the London 2012 Games. Chester: C\&W 2012Steering Group

Collins, J. C., \& Porras, J. I. (1996). Building your company's vision. Harvard Business Review, 74 (5), 65-77.

Cornelissen, S., Bob, U., \& Swart, K. (2011). Towards redefining the concept of legacy in relation to sport mega-events: Insights from the 2010 FIFA World Cup. Development Southern Africa, 28, 307-318.

Crompton, J. L. (1995). Economic -Impact analysis of Sport Facilities and Events 11 sources of Misapplication. Journal of Sport Management, 9, 14-35.

Crompton, J. L. (2006). Economic Impact Studies: Instruments for Political Shenanigans? Journal of Travel Research, 45, 67-82.

Deccio, C. and Baloglu, S. (2002). Nonhost Community Resident Reactions to the 2002 Winter Olympics: The Spillover Impacts. Journal of Travel Research, 41, 46-56.

Department for Culture Media and Sport (2007). Winning: A tourism strategy for 2012 and beyond. London: DCMS

Department for Culture Media and Sport (2008a). Before, During and After: Making the Most of the 2012 Games (Legacy Action Plan). London: DCMS

Department for Culture Media and Sport (2008b). Playing to win: A new era for sport. London: DCMS 
Diamond, J. (2005). Reflecting on the processes of a local evaluation: networks, narratives and partnerships. International Journal of Public Sector Management, 18, 178-189.

Dutton, J. E., Dukerich, J. M., \& Harquail, C. V. (1994). Organizational images and member identification. Administrative Science Quarterly, 39, 239-263.

Eisenhardt, K. M. (1989). Building theories from case-study research. Academy of Management Review, 14, 532-550.

Emery, P. (2010). Past, present, future major sport event management practice: The practitioner perspective. Sport Management Review, 13, 158-170.

Ferkins, L., \& Shilbury, D. (2012). Good Boards Are Strategic: What Does That Mean for Sport Governance? Journal of Sport Management, 26, 67-80.

Frisby, W., Thibault, L. \& Kikulis, L. (2004). The organizational dynamics of under managed partnerships in leisure service departments. Leisure Studies, 23, 109-126.

Gibson, H. J., Walker, M., Thapa, B., Kaplanidou, K., Geldenhuys, S. \& Coetzee,W. (2014). Psychic income and social capital among host nation residents: A pre-post analysis of the 2010 FIFA World Cup in South Africa. Tourism Management, 44, 113-122.

Girginov, V. (2011). Governance of the London 2012 Olympic Games legacy. International Review for the Sociology of Sport, 47, 543-558.

Girginov, V. \& Hills, L. (2009). The political process of constructing a sustainable London Olympics sports development legacy. International Journal of Sport Policy and Politics, 1, 161-181.

Glaser, B. G. \&. Strauss, A. L. (1967). The Discovery of Grounded Theory: Strategies for Qualitative Research, New York: Aldine de Gruyter.

Goodwin, M. and Grix, J. (2011). Bringing structures back in: the 'governance narrative', the 'decentred approach' and 'asymmetrical network governance' in the education and sport policy communities. Public Administration, 89, 537-556

Grant, R. M. (2003). Strategic planning in a turbulent environment: Evidence from the oil majors. Strategic Management Journal, 24, 491-517.

Gratton, C., Dobson, N. \& Shibli, S. (2000). The economic importance of major sports events: a case-study of six events. Managing Leisure, 5, 17-28.

Gratton, C., \& Preuss, H. (2008). Maximizing Olympic Impacts by Building Up Legacies. The International Journal of the History of Sport, 25, 1922-1938.

Gratton, C., Shibli, S. \& Coleman, R. (2006). The economic impact of major sports events: a review of ten events in the UK.' The Sociological Review, 54, 4158.

Grix, J. (2013). Sport Politics and the Olympics. Political Studies Review, 11, 1525.

Hallmann, K., Breuer, C. \& Kuhnreich, B. (2013). Happiness, pride and elite sporting success: What population segments gain most from national athletic achievements? Sport Management Review, 16, 226-235.

Hespe, C. (2010). London 2012 Games- Sports Legacy Agenda for Local Government. Kent: Local Government Association/ Kent County Council/ISPAL.

Hutt, M. D., Stafford, E. R., Walker, B. A. \& Reingen, P. H. (2000). Case study Defining the social network of a strategic alliance. Sloan Management Review, 41 (2), 51-62.

Huxham, C., \& Vangen, S. (2004).Doing things collaboratively: Realizing the advantage or succumbing to inertia? Organizational Dynamics, 33, 190201. 
Jennings, W. (2012). Why costs overrun: risk, optimism and uncertainty in budgeting for the London 2012 Olympic Games. Construction Management and Economics, 30, 455-462.

Jick, T. D. (1979). Mixing qualitative and quantitative methods - triangulation in action. Administrative Science Quarterly, 24, 602-611.

Kellett, P., Hede, A. M., \& Chalip, L. (2008).Social Policy for Sport Events: Leveraging (Relationships with) Teams from other Nations for Community Benefit. European Sport Management Quarterly, 8, 101-121.

Kornblatt, T. (2006). Setting the bar: preparing for London's Olympic legacy. Centre for Cities Discussion Paper 8. London: Centre for Cities/IIPR.

Leopkey, B., \& Parent , M. M. (2012a). The (Neo) institutionalization of legacy and its sustainable governance within the Olympic Movement. European Sport Management Quarterly, 12, 437-455.

Leopkey, B., \& Parent , M. M. (2012b). Olympic Games Legacy: From General Benefits to Sustainable Long-Term Legacy. International Journal of the History of Sport, 29, 924-943.

Lindsey, I. (2009). Collaboration in local sport services in England: Issues emerging from case studies of two local authority areas. International Journal of Sport Policy and Politics, 1, 71-88.

McDonald, I. (2005). Theorising partnerships: Governance, communicative action and sport policy. Journal of Social Policy, 34, 579-600.

Mintzberg, H. (1994). The fall and rise of strategic planning. Harvard Business Review, 72 (1), 107-114.

Mintzberg, H. \& Lampel, J. (1999). Reflecting on the strategy process. Sloan Management Review, 40 (3), 21-30.

Mitchell, R. K., Agle, B. R., \& Wood, D. J. (1997). Toward a theory of stakeholder identification and salience: Defining the principle of who and what really counts. Academy of Management Review, 22, 853-886.

Northwest Regional Development Agency (2007). Be inspired. Warrington: NWDA

Northwest Regional Development Agency (2009). Everyone's 2012. Warrington: NWDA

O'Brien, D. (2006). Event business leveraging - The Sydney 2000 Olympic Games. Annals of Tourism Research, 33, 240-261.

Parent, M. M. (2008). Evolution and issue patterns for major-sport-event organizing committees and their stakeholders. Journal of Sport Management, 22, 135-164.

Parent, M. M. (2010). Decision Making in Major Sport Events Over Time: Parameters, Drivers, and Strategies. Journal of Sport Management, 24, 291-318.

Parent, M. M. \& Harvey, J. (2009). Towards a Management Model for Sport and Physical Activity Community-based Partnerships. European Sport Management Quarterly, 9, 23-45.

Parent, M. M., Rouillard, C., \& Leopkey, B. (2011). Issues and Strategies Pertaining to the Canadian Governments' Coordination Efforts in Relation to the 2010 Olympic Games. European Sport Management Quarterly, 11, 337-369.

Pawlowski, T., Downward, P. \& Rasciute, S. (2014). Does national pride from international sporting success contribute to well-being? An international investigation. Sport Management Review, 17, 121-132.

Petersson, B. (2014).Still Embodying the Myth? Russia's Recognition as a Great Power and the Sochi Winter Games. Problems of Post-Communism, 61 (1), 30-40.

Phillpots, L., Grix, J., \& Quarmby, T. (2011). Centralized grassroots sport policy and 'new governance': A case study of County Sports Partnerships in the 
UK - unpacking the paradox. International Review for the Sociology of Sport, 46, 265-281.

Preuss, H. (2007). The Conceptualisation and Measurement of Mega Sport Event Legacies. Journal of Sport \& Tourism, 12, 207-228.

Provan, K. G. \& Milward, H. B. (2001). Do networks really work? A framework for evaluating public-sector organizational networks. Public Administration Review, 61, 414-423.

Sallent, O., Palau, R. \& Guia, J. (2011). Exploring the Legacy of Sport Events on Sport Tourism Networks. European Sport Management Quarterly, 11, 397421.

Siggelkow, N. (2007). Persuasion with case studies. Academy of Management Journal, 50, 20-24.

Smith, A. (2009). Spreading the positive effects of major events to peripheral areas. Journal of Policy Research in Tourism, Leisure and Events, 1, 231246.

Smith, A., \& Fox, T. (2007). From 'event-led' to 'event-themed' regeneration: The 2002 Commonwealth Games legacy programme. Urban Studies, 44, 11251143.

Stake, R. (1995). The Art of Case Study Research, Sage, London.

Stokes, R. (2006). Network-based strategy making for events tourism. European Journal of Marketing, 40, 682-695.

Strauss, A., \& Corbin, J. (1998). Basics of Qualitative Research : Techniques and Procedures for Developing Grounded Theory, Sage, Thousand Oaks, Calif.

Tien, C. L., Lo, H. C. \& Lin, H. W. (2011). The Economic Benefits of Mega Events: A Myth or a Reality? A Longitudinal Study on the Olympic Games. Journal of Sport Management, 25, 11-23.

Vangen, S. \& Huxham, C. (2003). Enacting leadership for collaborative advantage: Dilemmas of ideology and pragmatism in the activities of partnership managers. British Journal of Management, 14, S61-S76.

Vangen, S. \& Huxham, C. (2012). The Tangled Web: Unraveling the Principle of Common Goals in Collaborations. Journal of Public Administration Research and Theory, 22, 731-760.

Walton, H., Longo, A., \& Dawson, P. (2008). A Contingent Valuation of the 2012 London Olympic Games: A Regional Perspective. Journal of Sports Economics, 9, 304-317.

Weed, M., Coren, E., Fiore, J., Mansfield, L., Wellard, I., Chatziefstathiou, D., \& Dowse, S. (2009) A Systematic Review of the Evidence Base for Developing a Physical Activity and Health Legacy from the London 2012 Olympic and Paralympic Games. Canterbury Christ Church University: Centre for Sport, Physical Education and Physical Activity Research

Weed, M., Coren, E., Fiore, J., Mansfield, L., Wellard, I., Chatziefstathiou, D., \& Dowse, S. (2012). Developing a physical activity legacy from the London 2012 Olympic and Paralympic Games: a policy-led systematic review. Perspectives in Public Health, 132, 75-80.

Whittington, R. (1988). Environmental structure and theories of strategic choice. Journal of Management Studies, 25, 521-536.

Whittington, R. (2001). What is Strategy - and does it matter?, Thompson Learning, London.

Whittington, R., \& Cailluet, L. (2008). The crafts of strategy: Special issue introduction by the guest editors. Long Range Planning, 41, 241.

Wicker, P., Prinz, J., \& von Hanau, T. (2012). Estimating the value of national sporting success. Sport Management Review, 15, 200-210. 
Yin, R. K. (2003). Case Study Research : Design and Methods, Sage, Thousand Oaks, CA.; London.

Page | 26 